\title{
Multiple dimensional outreach activities attract students to the electro-optics program
}

Feng Zhou, Pat Scott, Devki Talwar

Feng Zhou, Pat Scott, Devki Talwar, "Multiple dimensional outreach activities attract students to the electro-optics program," Proc. SPIE 9666, 11th Education and Training in Optics and Photonics Conference, 966609 (5 June 2009); doi: 10.1117/12.2207937

SPIE Event: Eleventh International Topical Meeting on Education and Training in Optics and Photonics, 2009, St. Asaph, United Kingdom 


\title{
Multiple Dimensional Outreach Activities Attract Students to the Electro-Optics Program
}

Feng Zhou, Pat Scott and Devki Talwar

Indiana University of Pennsylvania

167 Northpointe Blvd, Freeport, PA 16229

\begin{abstract}
This paper discusses the basic formats of various outreach activities used to promote an engineering program in Electro-Optics (EO). These implemented outreach activities include school visits/classroom presentations, the on-campus EO Experience, EO Summer Camps, and Teacher \& Guidance Counselor Workshops. The effectiveness of these outreach activities were evaluated.
\end{abstract}

\section{Index Terms: outreach, engineering education}

\section{INTRODUCTION}

There is a constant decrease in the enrollment of electronics engineering program in recent years throughout most of the United States of America, due to a reduction in interest in the study of electronics engineering from high school students. By introducing high school students to the new and emerging technologies such as electro-optics, lasers, fiber optics and telecommunication, their perception has been changed and their interest has been stimulated. Electro-optics and optoelectronics, collectively known as photonics, is an enabling technology which has revolutionized the information storage, data communication, manufacturing, diagnosis, therapy, medical surgery, solid state lighting, display, space, defense and transportation in the past 40 years. As these advances surround our culture, it is vital to develop an educational program in electro-optics to train highly-qualified professionals for research organizations and private sectors, as well as to raise public awareness of the vast career opportunities in this cutting-edge discipline.

In 2002, Indiana University of Pennsylvania (IUP) launched an innovative degree program in Electro-Optics (EO) which offers two training options from associate's degrees to bachelor's degrees [1, 2]. In this paper, the extensive, multi-dimensional outreach activities are discussed that have been implemented successfully to attract students to the EO program [3-7]. The paper is organized as follows: Section I: Introduction; Section II: Electro-Optics Educational Pathway for High School Students; Section III: Outreach \& Recruitment Efforts; Section IV: Challenges of the Electro-Optics Program; Section V: Electro-Optics Program Evaluation; and Section VI: Summary.

\section{II. "2+2+2" EDUCATIONAL PATHWAY}

There is an immense demand for electro-optics engineers and technicians in the U.S. [8-10]. In order to meet the demand, a $2+2+2$ model has been used, which provides considerable flexibility. The multiple entrance and exit points allow young people to pursue vocational training and academic education in multi-disciplinary engineering areas such as electro-optics. The first level of the 2+2+2 Program provides students the opportunity to enter the program at the beginning of their junior 
year in high school. During their junior and senior year, students co-enroll in the appropriate math and science courses and four EO courses offered at a local cooperating career-technical school. Upon completion of these courses and an Advanced Placement Equivalency Course with the appropriate exam score, students can earn a certificate for the 15+ credits which can be articulated into IUP's associate degree program in EO. The second level of the 2+2+2 Program allows students to complete the 64 credits needed for the associate degrees in EO. After earning an associate's degree, students are prepared to move into technical positions in the EO industry. Students may exit the $2+2+2$ Program at this point or continue to the third level. The third level of the 2+2 Program allows students to transfer 64 credits from their coursework from the A.S.E.O toward a Bachelor degree in Electro-Optics.

After collaboration with EO companies to understand their current staffing needs, the nine courses were developed which serve as the core courses of the EO Program. These courses provide students with the necessary technical background and handon skills to move into EO related positions. The nine core courses include: Computer Interfacing in Electro-Optics (EOPT 105); Geometric Optics (EOPT 110); Introduction to Electronics (EOPT 125); Wave Optics (EOPT 120); Detection and Measurement (EOPT 210); Introduction to Lasers (EOPT 220); Fiber Optics (EOPT 240); High Vacuum Technology (EOPT 250) and Industrial Applications of Lasers (EOPT 260).

Because of the rapid emergence and interdisciplinary nature of the EO field, teaching strategies give highest priority to activities that encourage creativity, critical thinking and problem-solving skills. Furthermore, since the program is introduced early during the freshman and sophomore years in the University, emphasis is placed on concept development and qualitative analysis rather than mathematical derivations. In addition, emphasis is placed on the synergy among different EO core courses, which reinforces students' knowledge in this field.

Due to the hands-on skills necessary to succeed in the EO industry, each EO core course consists of a three-hour hands-on lab experiment in addition to two-hour lectures per week. Through these labs, students learn vital hands-on skills utilizing state-of-the art EO equipment. To complete each lab experiment, students are responsible for building the experiment without any preliminary setup. They select appropriate equipment available in the lab such as optical components (mounts and holders, etc.), light sources (light bulbs, LEDs, lasers, etc.) and measurement instruments (optical power meter, optical spectrum analyzer, etc.) to complete the experiment. After completing each lab, students are required to submit a formal lab report, documenting key concepts: objectives, basic theory, procedure, data collected, result analysis, discussion, and conclusions. In general, the lab component developed for this program reinforces the basic theory introduced during the class lecture and emphasizes: instruments and equipment used in the EO industry, basic optical experimental methods, and problem-solving skills [11-13].

Although the new " $2+2+2$ " EO program offers the advantage of early involvement of the students and flexibility of the entrance and exit points, outreach is a powerful tool to expose students to the excitement and challenges of engineering, and to the career and educational opportunities in this emerging high-tech field. More important, 
the outreach helps students to build their interests and gain the confidence necessary to pursue their interests. Also a higher retention is obtained when students make an informed decision about the best choice of major with all the necessary information provided.

\section{OUTREACH EFFORTS}

The various outreach activities, covering one or more components such as hands-on experience, interaction with faculty, staff, alumni and current students with the EO program, on-campus field trips, off-campus field trips, and social activities, are aiming for different groups: the students, school teachers and guidance counselors, and parents. As shown in Figure 1, a total of 4,233 local students have been reached from the fall of 2005 to the summer of 2008. On average, the outreach activities provided a direct impact to over 1,000 students every year. Table 1 provides the outreach breakdown by activity during 2006-2007. These outreach activities include school visits/classroom presentations, the on campus EO experience, career fairs, parent information sessions, the EO Summer Camp, and other outreach activities. The basic formats of different outreach activities are given in details below.

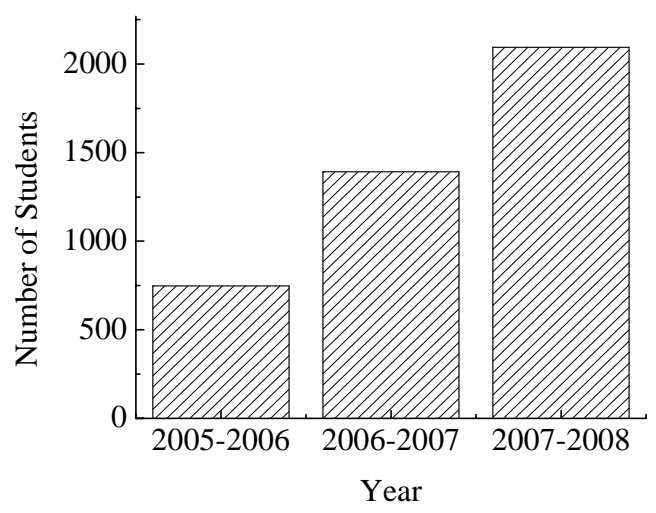

Fig. 1 Total number of students who attended outreach activities throughout fall of 2005 to summer of 2008.

Table 1 Outreach Breakdown by Activity in 2006-2007

\begin{tabular}{|l|c|}
\hline \multicolumn{1}{|c|}{ Outreach Activities } & Students Attended \\
\hline EO Experience On-Campus & 147 \\
\hline High School Classroom Visits & 709 \\
\hline High School Career Days & 403 \\
\hline "Starry Night" - Astronomy Night & 15 \\
\hline IUP Science Festival & 60 \\
\hline EO Summer Camp & 27 \\
\hline Total number of students reached & 1361 \\
\hline
\end{tabular}

A. High Schools Visits/Classroom Presentations

Classroom presentations provide an opportunity to speak to a large number of students in their sophomore and junior year. These presentations are arranged through a contact at the school, which is typically the physics or math instructor or 
school guidance counselor. Presentation style and format is dependent upon the time allotted. This can vary from 7 minutes to 1 hour in length.

Generally, the format of the presentation includes: an overview of EO engineering, potential career paths, the educational opportunities at IUP, and hands- on activities or demonstrations. Topics include:

- What is Electro-Optics Engineering?

- Careers and Job Outlook

- Hands-On Optics Activities

- $\quad 2+2+2$ EO Program at IUP

The classroom presentation increases awareness of the EO engineering at the highschool level. During the outreach, students learn about the specific field of engineering, the job opportunities, and the salary information. These examples in our daily life such as remote controls, DVD players, and digital cameras, are used to illustrate the wide applications of the EO engineering. Electro-Optics encompasses such technologies as: lasers, holograms, night vision and thermal imaging, and optical communication. In addition to this discussion, students learn about the emerging field of EO through portable hands-on activities which promote experimental education. These might include a magic stripes kit which has a basic polariscope that allows students to view the stress and strain of various transparent objects through crossed polarizers; a magic patch kit which incorporates a thin liquid crystal film with a good sensitivity at low temperatures; diffraction-grating glasses, night-vision scopes, and Optical Take-Home Theme Packets [14]. These materials are helpful to enhance students' understanding of EO at a variety of age levels. For example, by using the "Magic Patch", students are able to observe thermal-optical effects and gain an understanding of how liquid crystals are used in many electrooptical devices such as calculators and flat-panel displays. Diffraction-grating glasses are also distributed to students to view the diffraction of light as well as measure the grating spacing using a laser pointer.

Because there are many appealing and challenging EO careers for young people, an emphasis is placed on the importance and benefits that EO engineering brings to both one's quality of life and economic prosperity. A simple survey is conducted by the end of the presentation. From the survey conducted, the names of those students who indicated that they are interested in the EO program and would like to know more about the program are collected for the on-campus EO experience.

\section{B. The On-Campus Electro-Optics Experience}

For these students who expressed their interests in the EO program, they are invited to have a half day on-campus EO experience that runs approximately from 9am $12 \mathrm{pm}$. This outreach activity facilitates 30-40 high school sophomores-seniors who may come from different schools. Through funding from the Pennsylvania Department of Community and Economic Development (PA DCED), the bus transportation is provided to students for their on-campus field trips, as well as the pizza lunch.

Once there, the students are divided into two groups after a short introduction. One group (about 20 students) tours the labs and engages in a variety of hands-on lab 
activities with two instructors, one lab technician and several students currently enrolled in the EO Program. This group of students has the opportunity to participate in such activities as diffraction and the measurement of human hair diameter, fiber optics and fusing splice of two glass fiber ends, lasers and holography, spectroscopy and forensics applications, interferometry and DVD player, laser light show, etc. These topics may vary according to the background of students and requests from the school teachers such as EO applications in forensics or biology, etc. In addition to the lab component, the other group of students stays in a classroom and learns more about the principles behind each hands-on lab experiment, and further discusses about Electro-Optics and career opportunities in the field. A typical event itinerary is listed in Table 2.

Table 2 On-Campus Electro-Optics Experience

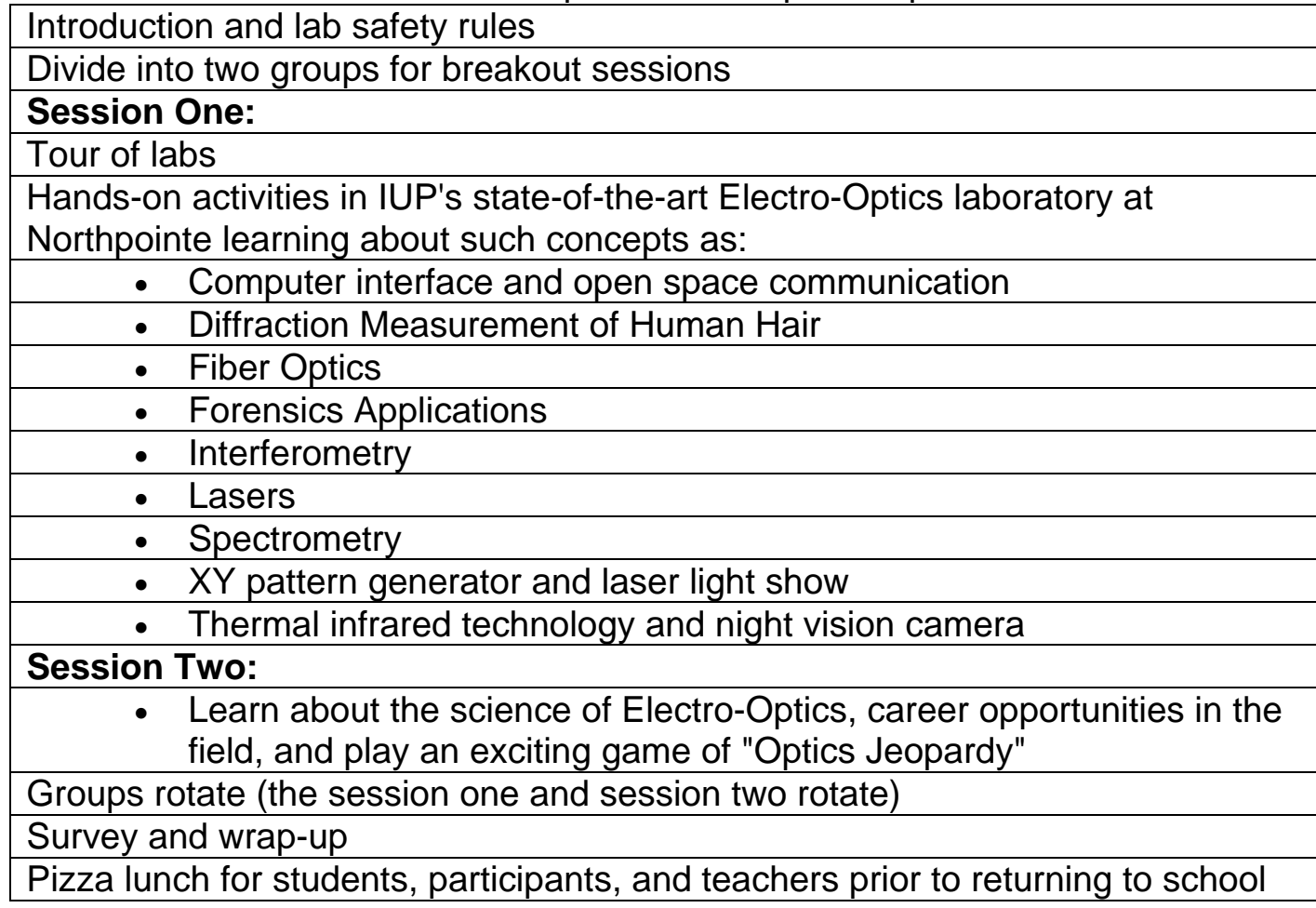

Every student and school teacher are surveyed to determine their opinion of the visit, interest in EO, and interest in future outreach and educational opportunities in the field. For example, a total of 147 high school students attended the on-campus EO experience in 2007. Approximately $40 \%$ of them expressed an interest in a career in Electro-Optics in the survey. The authors were impressed with the immense interest in EO after the on-campus field trip, as many had not been familiar with this field at the beginning of their visit.

\section{Electro-Optics Summer Camps}

For those high school students who indicated that they are interested in pursuing a career in EO, they are invited to attend a one-week day-camp free of charge during summer. The summer EO camp is also open to any students entering 10th, 11th, or 12th grade in the fall of the upcoming year. The summer camp is perhaps the most important and empowering par $t$ of the outreach programs. It unifies the various 
aspects of the outreach activities and gives students an idea of the types of resources available for classes. The first EO summer camp was offered in June of 2006 with the funding from PA DCED. The students take part in daily lectures which involve such topics as the nature of light, wave optics, electronics, fiber optics, holography, infrared imaging technology, lasers, robotics and nanotechnology, given by each instructor. Students are then guided through hands-on activities related to these advanced topics. For example, in Electronics, they learn how to solder and complete a simple transmitter and receiver set. In Optics, students are introduced to activities using a grating spectrometer and an interferometer. Table 3 displays the activities organized for the summer camp in 2009.

Table 32009 Summer Camp Schedule

\begin{tabular}{|l|l|}
\hline \multicolumn{1}{|c|}{ Time } & \multicolumn{1}{c|}{ Day 1 Activity } \\
\hline 8:30 am & Breakfast \\
\hline 8:45 a.m. & Welcome and Introductions \\
\hline 9:00 a.m. & Camp Pre-Test \\
\hline 9:30 a.m. & Nature of Light and Color Spectra \\
\hline 10:00 a.m. & Break \\
\hline 10:15 a.m. & Wave Optics and Interference Lab Activity \\
\hline 12:00 p.m. & Lunch \\
\hline 12:30 p.m. & Forensics Applications Activity \\
\hline 2:15 p.m. & Break \\
\hline 2:30 p.m. & "Green" Lab \\
\hline 3:45 p.m. & Wrap-Up \\
\hline 4:00 p.m. & Dismissal \\
\hline & \\
\hline 8:30 am & Breakfast \& Updates \\
\hline 9:00 a.m. & Electronics Project \\
\hline 10:00 a.m. & Break \\
\hline 10:15 a.m. & Electronics Project (continued) \\
\hline 12:00 p.m. & Lunch \\
\hline 12:30 p.m. & Electronics (continued) \\
\hline 1:00 p.m. & Tour: II-Vl \\
\hline 4:00 p.m. & Return to IUP Northpointe and Dismissal \\
\hline & \\
\hline 8:30 am & Breakfast \& Updates \\
\hline 8:45 a.m. & Adventures in Fiber Optics \\
\hline 10:00 a.m. & Break \\
\hline 10:15 a.m. & Adventures in Fiber Optics (continued) \\
\hline 12:00 p.m. & Lunch \\
\hline 12:30 p.m. & NASA Teleconference \\
\hline 1:45 p.m. & Tours: Sabeus, Dynamics Manufacturing and OSTI \\
\hline 4:00 p.m. & Return to IUP Northpointe and Dismissal \\
\hline & \\
\hline
\end{tabular}




\begin{tabular}{|l|l|}
\multicolumn{1}{|c|}{ Day 4 Activity } \\
\hline 8:30 am & $\begin{array}{l}\text { Nanotechnology Activity (Breakfast during } \\
\text { Presentation) }\end{array}$ \\
\hline 10:00 a.m. & Break \\
\hline 10:15 a.m. & Tour: Penn-State Electro-Optics Center \\
\hline 12:00 p.m. & Lunch \\
\hline 12:30 p.m. & $\begin{array}{l}\text { IR Camera Lab, Night Vision Lab, Robot and } \\
\text { Unmanned Aerial Vehicles Lab }\end{array}$ \\
\hline 1:50 p.m. & Return to IUP Northpointe and Break \\
\hline 2:00 p.m. & Work on Poster Presentations \\
\hline 4:00 p.m. & Dismissal \\
\hline 8:30 am. & \\
\hline 8:45 a.m. & Breakfast \& Updates 5 Activity \\
\hline 10:00 a.m. & Robotics \\
\hline 10:15 a.m. & Break \\
\hline 12:00 p.m. & Robotics (continued) \\
\hline 12:30 p.m. & Ronch \\
\hline 4:00 p.m. & Robotics (continued) \\
\hline 4:30 p.m. & Laser Light Show and Other Demonstrations \\
\hline 5:00 p.m. & Post-Test and Survey \\
\hline 5:30 p.m. & Poster/Project Presentations \\
\hline 6:00 p.m. & Closing Banquet and Award \\
\hline
\end{tabular}

To enhance the students' understanding of EO engineering and to gain in-depth information about the field, students are arranged to visit local Electro-Optics engineering companies and research laboratories specialized in the applications discussed. Some of the companies visited include II-VI Incorporated, world leader in $\mathrm{CO}_{2}$ laser optics and laser crystal growth technology; $\mathrm{L}^{3}$ Communications, producer of complex electro-optical and electro-mechanical systems and instrumentation for the commercial and defense markets; Sabeus, designer/manufacturer of fiber optics components; and the Penn State Electro-Optics Center who are renowned for lasers, night vision and robotics imaging. During these visits, the local EO companies shared information about internship and career opportunities in electro-optics engineering, which included examples of current projects underway at their companies.

Guest speakers are also invited to take part in the Camp to provide further insight into the field and its applications to various fields. A highlight to Summer Camp, for example, was a video-teleconference arranged with NASA's Jet Propulsion Laboratory in Pasadena, California, to provide insight into the significance of optical imaging. A Forensics Trooper from the PA State Police took part in Summer Camp 2008, who provided an overview of EO applications in forensics, and demonstrated alternate light sources and other techniques. 
Finally, a closing dinner was held at the end of the week which invited the studentparticipants and parents, as well as business and educational leaders. Students presented posters of their projects on topics introduced throughout the week and competed for various prizes. The projects completed individually or in small teams give the students a sense of accomplishment for the end of the camp and make the discipline immediately accessible. Attendees were impressed with the quality of the students' posters and had a difficult time choosing a winner. The winning posters were awarded such related prizes as Deflexion, an innovative laser board game that the students played during Camp. The informal interactions with faculty and staff during at meal time may be an additional advantage for students and parents. These camps have displayed a steady growth of interest in Electro-Optics. Due to the large attendance at the Electro-Optics Summer Camp in 2007, two Camps were offered during the summer of 2008 to provide more individualized attention to students and possible interaction throughout the activities. In 2009, the two camps were full, plus about 16 students in the waiting list. The average scores of the camp pre-test and post-test were $42 \%$ and $85 \%$, respectively, for the past three years. Also the students were asked to complete a survey at the end of the week. They were asked such questions as "How has this camp changed your understanding of Electro-Optics?" One student responded that it "greatly improved" his/her "understanding". Another student wrote, "I learned a lot more and this went beyond my expectations of Electro-Optics." Students were also asked how this Camp helped them make a decision about their future career. Some students wrote that this Camp helped them to decide on EO as their future career choice. Those students who attended the Summer Camps have formed the main pipeline for the EO program.

\section{EO Workshop for Teachers and Guidance Counselors}

As part of our long-term strategy, professional development activities such as workshops for local high-school personnel are also provided. Area math and science teachers and guidance counselors have been invited to take part in the "Electro-Optics Workshop" where they participate in hands-on EO activities that could be used in their classrooms. An overview of Electro-Optics, career and educational opportunities are also introduced. The workshop provides lecture components integrated with hands-on activities to gain insight into the field, as well as tours of local electro-optics companies and opportunities to meet IUP EO graduates currently working in the field. To promote further investigation, teachers/counselors also received kits with a curriculum guide to take back to their schools to teach their students about the exciting field of EO. The teacher/guidance counselor may earn Act 48 credit. Table 4 details the typical schedule of such a workshop.

Table 4 The Agenda of the EO Workshop for Teachers.

\begin{tabular}{|c|l|}
\hline Time & \multicolumn{1}{|c|}{ Topic } \\
\hline 8:30 a.m. & $\begin{array}{c}\text { Welcome - Continental Breakfast } \\
\bullet \quad \text { Introductions } \\
\end{array}$ \\
\hline 8:45 a.m. & Overview 48 sign-up \\
\hline
\end{tabular}




\begin{tabular}{|c|c|}
\hline & $\begin{array}{l}\text { - Electro-Optics Program } \\
\text { - Opportunities for students } \\
\text { o Classroom visits } \\
\text { o On-Campus EO Experience } \\
\text { o EO Summer Camp }\end{array}$ \\
\hline 9:30 a.m. & $\begin{array}{l}\text { Electro-Optics Lab Activities } \\
\text { - LED Color Kit }\end{array}$ \\
\hline 10:30 a.m. & Break \\
\hline 10:45 a.m. & - LED Color Kit (cont'd) \\
\hline 12:00 p.m. & Lunch \\
\hline 12:45 p.m. & Electro-Optics Career Opportunities \\
\hline 1:15 p.m. & $\begin{array}{ll}\text { Tours } & \\
\text { - Sabeus, Inc. } \\
\text { - Penn State Electro-Optics Center }\end{array}$ \\
\hline 2:30 p.m. & $\begin{array}{l}\text { Wrap Up } \\
\qquad \text { EO Resources } \\
\text { - Evaluation (required for Act } 48 \text { credit) }\end{array}$ \\
\hline
\end{tabular}

The survey results from 18 participants who attended this workshop in 2006 showed that $97 \%$ were satisfied with the workshop and 15 indicated that this workshop should be offered again. In addition, the teachers are told that the advanced EO lab facilities and diagnostic equipment on-campus are open to high-school classes for lab experiments. This may be especially beneficial to local high schools with poor science facilities. As the result, local school teachers have bought their students to experience advanced topics such as laser holography and nuclear radiation lab experiments by utilizing the state-of-the-art EO laboratories on-campus.

\section{E. Other Outreach Activities}

Apart from the outreach activities provided for the students, school teachers and guidance counselors, other outreach activities are launched for parents and more general audiences, such as Information Sessions for parents and Open Houses for the public. Area parents have been invited to attend an information session on Electro-Optics and tour the teaching facility and campus. Focus groups are invited to attend special topics such as "Women in Forensics", etc., with the hope that the number of female students in the program will increase. Over all, by holding these outreach activities, the area at large will be introduced to this emerging field and learns more about its career opportunities.

\section{EVALUATION}

For each outreach activity, a survey is conducted to gain feedback from the participants. The survey results collected indicate a favorable response to the activities organized and the interests generated. A typical result is shown in Table 5, which was the evaluation survey completed in 2007 by 42 students brought in by the guidance counselor, including 24 juniors and 18 sophomores, after the on-campus Electro-Optics Experience. 
Table 5 Evaluation Example for the Electro-Optics Science Experience

\begin{tabular}{|c|c|c|}
\hline \multicolumn{3}{|c|}{$\begin{array}{l}\text { 1. What was your favorite activity during the Electro-Optics Science } \\
\text { Experience today? }\end{array}$} \\
\hline Response & $\begin{array}{l}\text { Number of } \\
\text { students }\end{array}$ & $\begin{array}{l}\% \text { of total } \\
\text { students }\end{array}$ \\
\hline $\begin{array}{l}\text { Laser demonstrations/lab activities } \\
\text { Comments: } \\
\text { - "The lasers show and the pulsing laser" } \\
\text { - "Hands on experiences" } \\
\text { - "Playing with red and green lasers" } \\
\text { - "The sound rides with laser - if you interrupted } \\
\text { the laser the sound stopped!" }\end{array}$ & 18 & $43 \%$ \\
\hline $\begin{array}{l}\text { Jeopardy } \\
\text { Comments: } \\
\text { • "winning jeopardy" } \\
\text { - "playing jeopardy" }\end{array}$ & 8 & $21 \%$ \\
\hline Night Vision & 7 & $17 \%$ \\
\hline $\begin{array}{l}\text { Fiber Optics } \\
\text { Comments: } \\
\text { - "Cleaving fiber ends" } \\
\text { - "Splicing the optical fiber to form a necklace } \\
\text { with beads." }\end{array}$ & 7 & $15 \%$ \\
\hline Everything & 1 & $2 \%$ \\
\hline No comment & 1 & $2 \%$ \\
\hline \multicolumn{3}{|l|}{ Request for information about the following programs: } \\
\hline Interested in the Electro-Optics Program & \multicolumn{2}{|c|}{ Number of students } \\
\hline "Yes" & \multicolumn{2}{|c|}{$16(38 \%)$} \\
\hline
\end{tabular}

Of 147 students from 7 schools who attended the on-campus Electro-Optics Experience in 2007, approximately $40 \%$ of them expressed an interest in a career in Electro-Optics engineering. From these surveys, the effectiveness of the outreach activities is evaluated, and possible changes for future improvements are made. More important, students who are interested in EO engineering are identified.

For summer camps, pre- and post-tests are administered. For the past three years, the average scores of pre-test and post-test were $43 \%$ and $87 \%$, respectively, for a total of 118 campers (18 in 2006, 25 in 2007, 31 in 2008, and 44 in 2009). The survey statistics showed they had a valuable experience (4.78 out of 5 ), a better understanding of careers in science, math, and technology (4.73), and a better understanding of the field of electro-optics (4.82). However, some campers indicated in the survey that they were interested but will pursue science or engineering studies at other universities. To some degree, the increase of enrollment, the quality of students, retention, student academic performance and satisfaction can be viewed as measures of the success of the outreach activities. 


\section{SUMMARY}

The basic formats of four outreach activities for the newly established EO program at IUP have been discussed. As the only program, to our knowledge, which offers both associate's and bachelor's degrees in EO, it has successfully implemented a $2+2+2$ initiative that allows a wide range of students for entry into the rapidlyevolving EO workforce. In order to sustain its growth, a series of outreach activities have been offered to create an overall awareness of EO engineering in the community. The multi-dimensional approach has been carried out to achieve the short-term and long-term outreach strategies. Students, school teachers and parents are informed of the educational and career opportunities of the EO engineering field. The active and effective outreach activities have exposed the participants to the excitement of EO engineering through tours of on-campus labs, local EO engineering companies and research organizations. In addition, students experience an interesting learning process through the on-campus Electro-Optics field trip and EO Summer Camp, and the interactions with the faculty and stuff, students currently enrolled in the program and local EO professionals.

Various outreach activities have effectively attracted students to the EO program, as indicated by the continuous growth of student enrollment, the improvement of freshman quality, success of graduates and current students involved in the program, nearly $100 \%$ graduate job placement, and positive reviews from local industrial leaders. The reported outreach activities and outcomes are both interesting and useful to engineering education in general, and one or more formats discussed can be adapted and implemented to promote engineering programs.

\section{Acknowledgement}

The authors would like to express their appreciation for the support and funding received from the Pennsylvania Department of Community and Economic Development from 2005 -2009, the outreach grants from SPIE in 2007 and 2009, the grants from NSF ATE/OP-TEC in 2008 and 2009, and support from the Office of Naval Research and the Penn State Electro-Optics Center.

\section{REFERENCES}

[1] Feng Zhou, "Electro-Optics program at Indiana University of Pennsylvania", Proceeding of the Education and Training in Optics and Photonics Conference (ETOP 2005), pp 121-126.

[2] Patricia Scott, Feng Zhou, and Dorothy Zilic; "Applied Electro-Optics Educational and Training Program with Multiple Entrance and Exit Pathways", Proceedings of the Education and Training in Optics and Photonics Conference (EOPT 2007), Program Paper V. 
[3] Feng Zhou, and Christy Heid; "Promoting Electro-Optics to School Students through Summer Camp"; the Spring 2007 meeting of the AAPT of Western PA, Grove City, PA, (April 21, 2007)

[4] Christy Heid, and Feng Zhou, "Electro-Optics Outreach Activities", American Association of Physics Teachers (AAPT 2007) Summer Meeting, Greensboro, NC, USA (July 28-August 1, 2007)

[5] Patrick Huth, Feng Zhou, and Dorothy Zilic; "Outreach Focus of Applied ElectroOptics Training Program", Fall 2007 meeting of the Western Pennsylvania Section AAPT, 29 September 2007

[6] Grulick, John Pedrotti and Feng Zhou; "Building the High School Pipeline with Summer Photonics Institutes for High Schools", The National Career Pathways Network (NCPN) 2008 Annual Conference, Cincinnati, Ohio (October 22-25, 2008)

[7] Feng Zhou and Dan Hull; "Outreach Activities to Enlist High School Students for Electro-Optics Technician Program at Indiana University of Pennsylvania", OP-TEC Monograph (May 2009)

[8] W. Hardin, "Photonics in Defense," SPIE's OE Magazine, vol. 5, no. 4, p. 14, 2005.

[9] National Research Council, Harnessing Light - Optical Science and Engineering for the $21^{\text {st }}$ Century, Washington, D.C.: National Academy Press, 1998, p. 76.

[10] B. D. Johnson, "The U.S. photonics job market: Recruiting for the future," Photonics Spectra, vol. 36, pp. 97-99, 2002.

[11] Feng Zhou, Gregory Helmininack, and Christy Heid, "A portable vacuum mass spectrometer for undergraduate laboratory", American Association of Physics Teachers (AAPT 2007) Summer Meeting, Greensboro, NC, USA (July 28-August 1, 2007)

[12] Greg Helmininack, Derek Gladysiewski, Feng Zhou, Ken Hershman, Ben Campbell and Jeff Thomas "Supercontinuum Generation in Photonic Crystal Fibers for Undergraduate Laboratory", Education and Training in Optics and Photonics Conference (EOPT 2007), Ottawa, ON, Canada (June 3-6, 2007)

[13] Feng Zhou, and Todd Cloninger; "Determining of Planck's constant using LEDs", The Physics Teacher, 46, 413 (2008)

[14] S. D. Jacobs, L.L. Gregg, C. M. Andrews and R. L. Coppens, "Optics Suitcase," University of Rochester, NY, 2000. 